

\section{Análise sobre o planejamento turístico na Bahia e seus reflexos na Ilha de Itaparica (BA)}

Analysis of the tourist planning in Bahia and its reflexes in Itaparica Island (BA)

Chelly Costa Souza ${ }^{1}$

Regina Celeste de Almeida Souza ${ }^{2}$

\footnotetext{
${ }^{1}$ Doutora em Desenvolvimento Regional e Urbano (2016). Mestre em Análise Regional (2008), MBA em Administração (2003) e Bacharel em Turismo (2000). Toda a formação cursada na Universidade Salvador - UNIFACS. Tem experiência na área de Turismo e Hotelaria atuando principalmente nas seguintes áreas: Hotelaria e Planejamento Turístico. É docente do Instituto Federal de Educação Básica, Técnica e Tecnológica - IFBA - Campus Salvador/Bahia do Curso Técnico de Hospedagem e Superior de Tecnologia em Eventos. chellycsouza@yahoo.com.br/ chelly@ifba.edu.br

2 Pós-doutorado pela Université de Toulouse II (Le Mirail), França, (1986-1987) e pelo Centre d’Etudes Técniques de I'Equipament de Lyon, CETE, França (1992-1992). Doutorado em Geografia pela Universidade de Rouen, França (1981). Mestrado em Ciências Humanas pela Universidade Federal da Bahia (1976). Graduação em Geografia pela Universidade Federal da Bahia (1970) e graduação em História pela Universidade Católica do Salvador (1967). Atualmente é professor titular do Programa de Pós-graduação em Desenvolvimento Regional e Urbano da Universidade Salvador- Unifacs, atuando principalmente nos seguintes temas: Turismo, Meio Ambiente, Desenvolvimento Regional. Líder do Grupo de Pesquisa em Turismo e Meio Ambiente - GPTURIS vinculado ao Programa de Pós-graduação em Desenvolvimento Regional e Urbano. regina.souza@unifacs.br
} 


\title{
Resumo
}

A Ilha de Itaparica (BA), já se destacou, no cenário nacional e internacional, como um importante destino turístico brasileiro. Entretanto, no contexto atual, essa região enfrenta dificuldades de ordem social e econômica, ainda que sua atividade predominante seja o turismo. Diante disso, o presente estudo analisa o planejamento turístico na Bahia e seus reflexos na llha de Itaparica (BA), no período de 2004 a 2014, com enfoque para os possíveis desdobramentos do Programa de Desenvolvimento do Turismo - PRODETUR/NE na llha. Para tanto, optou-se pela metodologia qualitativa e pelo método do estudo de caso. Conjuntamente, o estudo envolveu a pesquisa bibliográfica, cartográfica e documental, além de entrevistas e observação direta. Os resultados indicaram que os principais problemas encontrados devem-se, em grande parte, à falta de um planejamento direcionado, à falta de interesse da atuação do poder público, assim como, à ausência de uma parceria entre os setores envolvidos.

Palavras-chave: Planejamento Turístico. Políticas Públicas. PRODETUR/NE. Ilha de Itaparica (BA).

\begin{abstract}
Itaparica Island (BA) was long known national and internationally as a major tourist destination in Brazil. However, in the present situation, this region faces difficulties in social and economic order, although its main activity is tourism. Based on that, this study focuses on tourism planning in Bahia and its reflections in Itaparica Island (BA), from 2004 to 2014, emphasizing on the possible developments of the Tourism Development Program - PRODETUR / NE in the Island. For that, we chose the qualitative methodology and the case study method.This study involved bibliographical, cartographic and documentary research, as well as interviews and direct observation. The results indicated that the main problems are due in large part to the lack of tourism planning, lack of interest of the public power, and lack of a partnership between the sectors involved.
\end{abstract}

Keywords: Tourism Planning. Public Politics. PRODETUR/NE. Itaparica Island.

\section{Introdução}

O presente artigo é um recorte da tese de doutorado em Desenvolvimento Regional e Urbano, no âmbito do Programa de Pós-Graduação em Desenvolvimento Regional e Urbano PPDRU, pela Universidade Salvador (UNIFACS), defendida no ano de 2016 e intitulada "Sob o sol da Bahia: uma análise do planejamento e da dinâmica da atividade turística na llha de Itaparica". Nela, buscamos analisar, de forma ampliada, as inter-relações entre o planejamento e a dinâmica da atividade turística na Bahia, considerando, especialmente, as políticas públicas e suas consequências em âmbito estadual baiano, bem como, de forma mais específica, os seus desdobramentos (ou ausência destes) na Ilha de Itaparica (BA), no decurso do decênio de 2004 a 2014.

No recorte ora apresentado, nos detemos resumidamente na apreciação de alguns dos pontos discutidos na tese. Em razão disso, optamos por expor um breve apanhado sobre a atividade turística insular, bem como uma retomada sobre essa atividade na llha de Itaparica e o planejamento público. Além disso, apresentamos brevemente a metodologia utilizada na tese e as principais conclusões encontradas ao longo do processo de pesquisa.

Com o presente estudo, objetivamos analisar o planejamento turístico na Bahia e seus reflexos na llha de Itaparica (BA), com base nos entrelaçamentos entre planejamento turístico, 
políticas públicas de promoção do turismo e a atividade turística na Ilha. Para tanto, a abordagem compreende três seções, além da introdução e das considerações finais: Turismo insular e atividade turística na llha de Itaparica (BA), Planejamento Turístico, Políticas de Turismo e seus reflexos para a Ilha de Itaparica (BA) e Procedimentos metodológicos.

Na primeira parte, são apresentados os aspectos históricos e econômicos da llha de Itaparica, com fins à observação do desenvolvimento da atividade turística nessa região, bem como um decurso histórico da atividade turística nos territórios investigados, dando ênfase ao período de análise (2004 - 2014). Em Planejamento Turístico, Políticas de Turismo e seus reflexos para a Ilha de Itaparica (BA), por sua vez, discutimos o planejamento turístico ocorrido na Bahia e suas interrelações com as políticas públicas de promoção do turismo na região, em especial a partir do programa PRODETUR/NE II e sua correlação com a Ilha de Itaparica, tendo como principal enfoque o decênio de 2004 a 2014. Por fim, em Procedimentos metodológicos, há uma breve explicação sobre quais foram os métodos e procedimentos abordados utilizados como amostragem para a discussão ora apresentada.

\section{Turismo insular e atividade turística na llha de Itaparica (BA)}

A atividade turística é considerada um fenômeno das sociedades modernas, responsável pelo incremento da economia, pela produção e/ou utilização de espaços e pelo intercâmbio de culturas e pessoas. Na esteira do crescimento dessa atividade, enquadra-se o turismo em ilhas, as quais são veiculadas pela mídia como destinos turísticos preciosos, exóticos, sagrados e diferentes, por sua concepção de isolamento, o que os diferiria dos outros territórios. Para Assis (2001a), a questão do isolamento das ilhas favorece a ideia de quebra de rotina, uma vez que apresenta a sensação de refúgio. Além disso, o público interessado nesse destino turístico, em particular, procura por um clima diferente, belas paisagens, sol e praia - elementos que compõem o que os especialistas denominam de turismo litorâneo, popularmente conhecido como Turismo de Sol e Praia. Em alguns casos, nos quais há uma extensão maior do período em que o turista fica hospedado na localidade, há a ocorrência do Turismo de veraneio/segunda residência, cujas características estão atreladas, no Brasil, de forma muito especial ao Turismo de Sol e Praia.

Dessa forma, o turismo em ilhas apresenta diferentes particularidades que são manifestadas pela interação de múltiplos fatores, tais como localização, tamanho, infraestrutura, práticas socioespaciais, entre outros. Em razão desses múltiplos fatores, na história do turismo na Bahia, a Ilha de Itaparica (BA) - composta pelos municípios de Itaparica e Vera Cruz - durante muito tempo, destacou-se turisticamente no âmbito nacional e internacional. Entretanto, atualmente, a atividade turística nessa região tem passado por um expressivo dinamismo - diminuiu significativamente e a 
região vem enfrentando graves problemas econômicos e sociais, mesmo mantendo na localidade o turismo de sol e praia, bem como o de veraneio/segunda residência.

A presente investigação elegeu como período de análise o decênio de 2004 a 2014, pois, nesse transcurso temporal, inferimos que há o ressurgir de uma esperança quanto à atividade turística na llha de Itaparica, em razão da implementação de políticas públicas de turismo, em particular das diretrizes do Programa de Desenvolvimento do Turismo no Nordeste II PRODETUR/NE II, em sua segunda fase. Nesta, esse espaço insular seria beneficiado com recursos advindos do referido programa, ainda que essa região venha de um sofrido processo de desgaste em relação ao declínio da atividade turística na região, em anos anteriores, como analisou Soares (2003). Entretanto, mesmo com os problemas apresentados, os quais vão da falta de investimento às deficiências nas estruturas básicas de acesso e de serviços, se mantém na localidade o turismo como principal atividade econômica.

A llha de Itaparica (BA) é uma área litorânea situada na macrorregião do Recôncavo da Bahia, composta por dois espaços geograficamente integrados, os municípios baianos de Vera Cruz e Itaparica. Insere-se na Baía de Todos os Santos e faz parte da Zona Turística e Área de Proteção Ambiental (APA) da Baía de Todos os Santos (BTS). Igualmente pertence à Região Metropolitana de Salvador (RMS), considerada a mais rica do estado em termos econômicos, sendo bem integrada à capital - Salvador, principalmente por causa de sua posição geográfica estratégica, a qual se liga à cidade de Salvador e a outros importantes municípios do interior do estado. A seguir, a figura 01, intitulada Mapa da Baía de Todos os Santos, apresenta o recorte territorial da Ilha de Itaparica a ser analisado. 

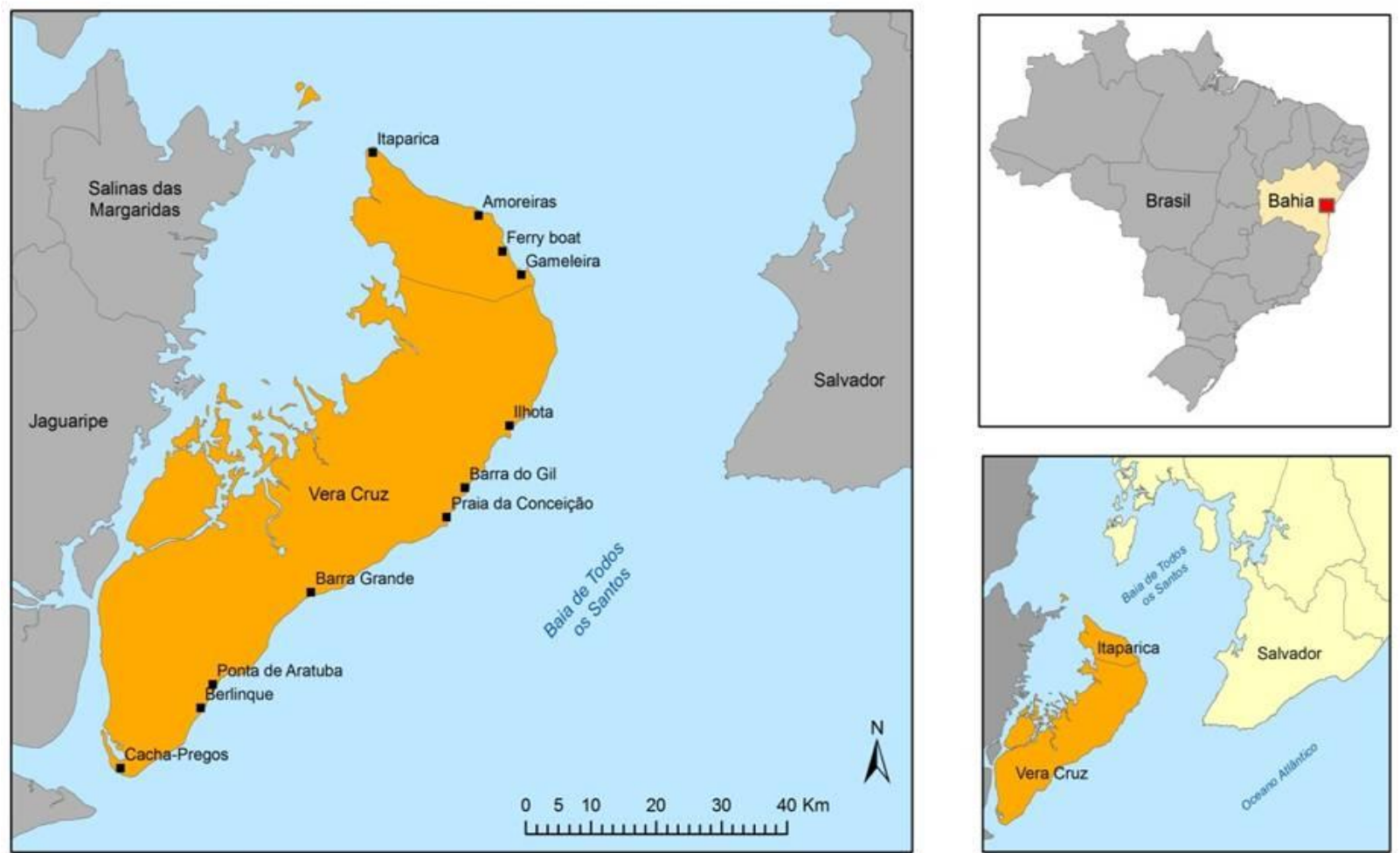

Fonte: www. coapatur.com.br

Título: Mapa de localização da Ilha de Itaparica

Fonte: www.coapatur.com.br

Organização: Ricardo Bahia

A Ilha de Itaparica apresenta uma área de $246 \mathrm{~km}^{2}$, no qual vivem cerca de 58.292 pessoas, sendo 20.725 habitantes no município de Itaparica e 37.597 no município de Vera Cruz (IBGE, 2010). Em relação à economia da Ilha, destacam-se: a pesca, o comércio (que atende às necessidades locais) e a atividade turística. Desses setores, o turismo é o que dá maior dinamização ao cenário econômico da região. Desse modo, considerando que o sol e a praia sejam as principais motivações para as pessoas que frequentam essa região, o período do verão (em particular, nos meses de dezembro, janeiro e fevereiro) é a época em que há uma maior movimentação em torno dessa atividade no espaço em questão.

Historicamente, nessa região, o turismo passou por diversas fases e teve início oficialmente a partir do ano de $1939^{3}$, quando a localidade recebeu o título de estância hidromineral ${ }^{4}$. Nesse contexto, o desenvolvimento da atividade na região começou a ocorrer em torno da Fonte da Bica

\footnotetext{
${ }^{3}$ Desde 1877 já se registram notícias de sua ocupação como estação de cura e local de veraneio, conforme indica Osório (1928).

${ }^{4}$ Esse fato corroborou para a solidificação de Itaparica como balneário e local de turismo. A estância tem como eixo central a Fonte da Bica, importante local da cidade, com águas medicinais, cuja construção data de 1842 e tem por singularidade ser a única estância hidromineral do país à beira-mar.
} 
em virtude dos hábitos populacionais. Era um hábito social secular passar as férias ou temporadas de descanso fazendo uma "estação de águas", isto é, as temporadas de lazer se concentravam em regiões de estâncias termais e hidrominerais.

Durante muito tempo, na Bahia, essa foi a principal motivação dos primeiros fluxos turísticos registrados no estado. Gradativamente, a percepção social e comercial passou a ver nesses fluxos uma possibilidade de investimento turístico e, em virtude disso, em especial na década de $1950^{5}$, houve o desenvolvimento do turismo em Itaparica de forma mais estruturada, a partir de fatos como a construção do Grande Hotel de Itaparica ${ }^{6}$, no ano de 1954. Este empreendimento marcou a fase áurea da Ilha diante do grande fluxo de turistas que a região recebia na época.

Em seguida (década de 1970), outros três importantes fatos aconteceram: a implantação do Sistema Ferry Boat, com a construção da rodovia BA-001; a construção da Ponte do Funil; e a inauguração do primeiro hotel de grande porte, um resort pertencente a uma cadeia internacional de hotéis e resorts, o Club Mediterraneé - Club Med, situado na Praia de Conceição, pertencente ao município de Vera Cruz. A instalação desse resort foi um dos marcos de consolidação da ilha enquanto destino turístico, principalmente, na rota das grandes cadeias internacionais.

Na década de 1980, ocorreu a criação do Programa Caminhos da Bahia, cujo objetivo foi estimular a atividade turística no interior do estado, com vistas ao incremento do fluxo nacional e/ou regional, na direção das cidades de grande potencial turístico, situadas principalmente nas redondezas da BR-101, com destaque para os municípios de Itaparica e Vera Cruz. Contudo, ainda na década de 80, o segmento turístico passou a entrar em dificuldades.

Segundo Santos (2011), ao analisar as potencialidades econômicas da Ilha de Itaparica, o autor identificou que a falta de atividades econômicas possíveis para dar suporte ao crescimento demográfico e a ausência de investimentos públicos foram suficientes para promover pontos críticos na região, a exemplo da degradação ambiental, do patrimônio histórico e cultural, elementos considerados imprescindíveis para o uso turístico.

De acordo com Soares (2003), há um entendimento, no senso comum, de que, com o passar do tempo, a llha se transformou em território das classes sociais mais baixas. Do mesmo modo, há a compreensão de que o surgimento de outros destinos, com maior facilidade de deslocamento, maior número de serviços aliados aos fatores preço e qualidade, fez com que a llha ficasse esquecida pelos órgãos competentes de turismo e pelo próprio turista durante o final do século XX.

\footnotetext{
${ }^{5}$ Ressaltamos que desde a década de 1930 existiram ações pontuais que tornaram o turismo uma realidade regional na llha de Itaparica. Contudo, era algo esporádico e explorado de forma não específica e não especializada.

${ }^{6}$ O Grande Hotel de Itaparica, primeiro Hotel Cassino da Bahia, construído em 1950 e conhecido como centro preferido de lazer e repouso da sociedade na Bahia. Até início da década de 1980, teve momento de ápice e recebeu personalidades ilustres do cenário regional, nacional e até internacional. Na atualidade é administrado pelo Serviço Social de Comércio (SESC) desde o ano de 2006 (GAUDENZI, 2008).
} 
Em se tratando da llha de Itaparica, nesse sentido, o deslocamento é algo que deve merecer atenção. Isso porque, após a instalação do sistema de ferry boat, alguns problemas começaram a surgir. A principal dificuldade desse modo de transporte foi e continua sendo a formação de imensas filas de pessoas e carros que aguardam para atravessar, principalmente no período do verão (SOARES, 2003).

Em paralelo, por sua vez, a Estrada do Coco, aberta no ano de 1975, e sua extensão, a Linha Verde - rodovia que se estende de Praia do Forte até o município de Jandaíra e/o Litoral Norte da Bahia ou a BA-099, começaram a receber atenção de forma intensa e a influenciar nas perspectivas futuras para a ilha. Além disso, a construção desse novo acesso criou condições favoráveis para o desenvolvimento do turismo, com extensão de $140 \mathrm{~km}$ de praias, até então inexploradas, em uma curta distância do Aeroporto Internacional de Salvador (Luís Eduardo Magalhães).

Assim, houve um redirecionamento de um número significativo de pessoas que tinham a llha de Itaparica como destino. Elas passaram a buscar outros atrativos como novidade, num primeiro momento, entretanto, posteriormente, tornou-se uma espécie de via definitiva. Além disso, as regiões da Baía de Todos os Santos e a Costa dos Coqueiros (estratégia de divisão das regiões turísticas) passaram a fazer parte da lista de prioridades do governo estadual. O potencial da Costa dos Coqueiros, de acordo com Gaudenzi (1998), estava mais do que comprovado. Tal fato se confirma a partir do volume de investimentos da iniciativa privada que essa região atrai e continua a atrair, após a construção da Linha Verde.

Enquanto isso, a Ilha de Itaparica continuou a se deparar com sérias dificuldades. A ausência de outras atividades econômicas para dar apoio ao crescimento demográfico que se observa na ilha e, igualmente, a ausência de investimentos públicos são avaliadas como pontos críticos dos municípios e que têm como consequência a degradação ambiental, do patrimônio histórico e cultural, vistos como potencialidades de Itaparica para o seu desenvolvimento (ITAPARICA, 2004, p. 5.02).

No período de 1991-2002, a Bahia apresentou uma expansão considerável na atividade turística, a qual respondia em torno de 7,9\% da economia baiana. Nessa ocasião, o turismo ainda era a atividade que dava maior dinamização ao cenário econômico da ilha de Itaparica. Porém, foi nessa década de 1990 que a llha de Itaparica começou a sentir os efeitos da concorrência de outros destinos, com potenciais turísticos semelhantes, os quais começavam a atrair a atenção de visitantes e de investimentos advindos do poder público e privado. Assim, a llha de Itaparica perdeu o seu glamour e passou a experimentar um processo de desvalorização das propriedades, chegando, inclusive, a um movimento de favelização em determinadas áreas (ITAPARICA, 2003-2005, p. 5.08- 
5.09). A esta situação, somou-se a falta de investimentos em infraestrutura por parte das três instâncias governamentais.

Daí em diante, os atrativos naturais e culturais tornaram-se "desinteressantes" e a ilha passou a perder a visitação de (muitos) visitantes/ turistas e veranistas que aproveitavam a sua paisagem (sol e mar) durante a alta estação. A llha de Itaparica começou a se deparar com os efeitos de degradação em seu território. Do mesmo modo, a feição urbana e a sua interface social passaram a demonstrar sinais de saturação e insustentabilidade no padrão de ocupação e uso do solo (SOARES, 2003). Contudo, mesmo diante desse cenário de transformações, degradação e falta de investimentos em prol de sua revitalização, a atividade turística ainda acontecia de forma oscilante, com características de pendularidade, qualificada pelo fluxo de turistas (visitantes) que passavam o dia na Ilha de Itaparica, mas se hospedavam na capital baiana.

A preferência pela hospedagem em Salvador pode ser explicada pela proximidade entre as localidades e pela existência de problemas na infraestrutura básica da ilha. Ou, também, de modo mais específico, pela falta de atenção ao turismo propriamente dito nessa região, o que se observa de modo mais acentuado a partir dos anos 90. Já no decênio de 2004 a 2014 (período de análise desse estudo) houve o ressurgir de uma esperança quanto ao ressurgimento mais acentuado da atividade turística na llha, uma vez que também foi nessa época que houve a introdução da segunda fase de um importante programa: o Programa de Desenvolvimento do Turismo no Nordeste II do PRODETUR/NE II (2003 ${ }^{7}$ a 2012), no qual a Ilha de Itaparica seria beneficiada com recursos advindos desse programa.

\section{Planejamento Turístico, Políticas de Turismo e seus reflexos para a llha de Itaparica (BA)}

Considerando que o presente estudo centra a análise nas inter-relações entre o planejamento da atividade turística na Bahia e seus reflexos para a llha de Itaparica (BA) no período de 2004 a 2014, tendo como principal diretriz o PRODETUR-NE II, é fundamental apresentarmos nossos entendimentos quanto ao planejamento, no que tange à prática do turismo. Bem como, analisarmos também as políticas públicas enquanto pilares desse planejamento, como um dos fatores que influenciam a realização da atividade turística.

A atividade turística é vista como um dos setores econômicos que mais cresce no Brasil e em função do segmento sol e praia apresentar uma posição de destaque, o governo federal brasileiro organizou um conjunto de ações e diretrizes que originaram e fomentaram políticas públicas pautadas no planejamento sistemático e organizado desse setor. Historicamente, o conceito de planejamento se constrói como o conjunto de ações que buscam instituir o controle social sobre

\footnotetext{
${ }^{7}$ Com início em 2005.
} 
bens, serviços e obras públicas, de modo que estes sejam desfrutados de maneira efetiva por toda a sociedade.

Observamos, assim, que, com base no planejamento, uma política pública pode ser definida como o desenvolvimento da atividade política. Para o Ministério do Turismo, a política pública,

sinaliza um tipo de orientação para a tomada de decisões em assuntos públicos, políticos ou coletivos. A implementação e Gestão das Políticas públicas é responsabilidade de atores políticos, nos mais diversos âmbitos da administração pública (BRASIL, 2009, p. 47).

O Planejamento do Turismo, segundo Molina e Rodríguez (2001), é o resultado de um processo lógico de pensamento, no qual tem como objetivo uma mudança na ordem econômica e social de um povo. Porém, ao enveredar por esse campo, é importante considerar a complexidade estrutural que envolve o turismo, processá-la, instrumentalizá-la a fim de promover mudanças que atuem como alavancas do desenvolvimento. Disso resulta que a maneira adequada de planejar incide em analisar objetivamente uma realidade e condicionar as ações ao problema.

Assim, o planejamento turístico representa o instrumento fundamental na determinação e seleção de prioridades, deve ordenar as ações do homem sobre o território, por meio de um processo sistemático no qual há a definição de objetivos, estudos, análises, formulação de planos e indicações e implantação de uma gestão contínua. Esta, por sua vez, tem como objetivo promover o desenvolvimento do turismo de forma harmoniosa, através de mudanças estruturais de realidades existentes e da geração do crescimento econômico acelerado. Dessa forma, podemos afirmar que o Planejamento Turístico continua e sempre será um instrumento valioso e que serve para orientar o sistema turístico.

É justamente em virtude dessa funcionalidade e vital importância do planejamento para a atividade turística que nos propusemos a estudar o Programa de Desenvolvimento do Turismo no Nordeste (PRODETUR/NE) e seus reflexos na Bahia, tendo como especial enfoque os desdobramentos desse plano de ação na Ilha de Itaparica. O PRODETUR/NE, instituído pelo governo federal, teve como objetivo a intensificação do turismo nos territórios nordestinos, o que foi acolhido pelos governos estaduais como forma de introduzir e aprimorar a atividade turística nessas regiões, em especial voltadas às áreas litorâneas. Assim, era possível melhorar os aspectos de infraestrutura básica e de acesso, bem como promover a geração de renda e emprego e a minimização das desigualdades inter-regionais.

O modelo definido no referido programa passa pela ordenação do espaço turístico. No caso da Bahia, adotou-se como metodologia a subdivisão territorial do estado, enquadrando a inclusão de quatro grandes regiões, denominadas de Regiões Turísticas: Salvador; Entorno Metropolitano (Baía 
de Todos os Santos - zona onde a Ilha de Itaparica está situada e Litoral Norte) ${ }^{8}$; Litoral Sul e Chapada Diamantina. Depois, esse zoneamento foi aperfeiçoado e deu origem ao estabelecimento de sete zonas ${ }^{9}$ turísticas na Bahia (MATTEDI, 1999, p. 23). Cada estado desenhou os seus projetos na área de turismo. Por esse motivo, cada área específica do litoral nordestino passou a fazer parte do PRODETUR e assim estava dividido, conforme explica a autora:

No Maranhão, foi escolhida Alcântara, no golfão maranhense; no Piauí, a Costa das Dunas; no Ceará, a Costa do Sol Poente; no Rio Grande do Norte, a Rota do Sol; na Paraíba, o Centro Turístico do Cabo Branco; em Pernambuco, o Centro Turístico de Guadalupe que, com uma área do litoral de Alagoas, forma a Costa Dourada; em Sergipe, a Zona Turística de São Cristóvão; na Bahia, a Costa dos Coqueiros e a Costa do Descobrimento, e em Minas Gerais, os sítios arqueológicos e ecológicos de Montes Claros.

Na primeira fase do Programa, o Governo estadual concentrou a maior parte dos investimentos (57\%) na Costa do Descobrimento, principalmente no município de Porto Seguro, Santa Cruz de Cabrália e Belmonte. Em seguida, Baía de Todos os Santos (31\%) - destaque para a capital do estado, Costa dos Coqueiros (21,6\%), Costa do Dendê e Costa do Cacau. No tocante à Ilha de Itaparica, entretanto, os municípios de Vera Cruz e Itaparica não tiveram nenhum tipo de participação no que se refere às obras realizadas no PRODETUR I, mesmo a região estando incorporada na zona turística Baía de Todos os Santos. A cidade de Salvador recebeu os maiores investimentos $(44,7 \%)$, dos recursos públicos, favorecendo dessa maneira, a liderança como um centro turístico baiano importante. Esse fato, inclusive, contraria o que foi definido no início do Programa, já que a Bahia havia proposto como região prioritária para os investimentos a Costa dos Coqueiros e a Costa do Descobrimento.

Além disso, a llha de Itaparica não foi contemplada porque o PRODETUR I se concentrou menos nessa região (Baía de Todos os Santos) e mais na Costa do Descobrimento. Cabe acrescentar que a llha só foi contemplada a partir da 2a fase do PRODETUR. Contudo, ainda assim, ressaltamos que O PRODETUR/NE I foi avaliado como uma experiência diferente e importante para a reestruturação dos territórios. Isso porque estimulou novos investimentos e contribuiu para o crescimento econômico das regiões beneficiadas, sendo considerada uma política diversa em termos de fomento em turismo.

Devido aos resultados de sucesso do PRODETUR I, surgiu a criação e consequente aplicação do PRODETUR II, cuja finalidade foi o de melhorar a qualidade de vida da população dos polos turísticos, situados no litoral nordestino, através da capacitação profissional. Também teve como

\footnotetext{
${ }^{8}$ Essa zona turística abrange a capital do Estado (Salvador), além dos municípios de Cachoeira, Itaparica, Jaguaripe, Madre de Deus, Maragojipe, Nazaré, Salinas de Margarida, Santo Amaro, São Félix, São Francisco do Conde, Saubara e Vera Cruz. É considerado o principal portão de entrada para o turista que visita a Bahia (www.setur.gov.br/guia-do-investidor/geografiado-turismo). Acesso em 25 de Fevereiro de 2015.

${ }^{9}$ Costa dos Coqueiros; Baía de Todos os Santos; Costa do Dendê; Costa do Cacau; Costa do Descobrimento; Costa das Baleias; Chapada Diamantina.
} 
foco apoiar os investimentos e ações para gerar renda turística e garantir que os governos municipais gerenciassem de forma eficaz os investimentos e fluxos de turismo, além de promover benefícios para a população permanente.

No estado da Bahia foram definidas quatro regiões estratégicas que seriam beneficiadas nessa etapa (Costa do Descobrimento; Chapada Diamantina; Litoral Sul; e Salvador e Entorno) e 91\% das ações foram executadas entre os anos de 2007 e 2011 (BAHIA, 2012). Reportando-nos sobre os investimentos do PRODETUR II voltados para a llha de Itaparica, podemos mencionar que, somente nessa fase, esse espaço recebeu investimentos em infraestrutura. As obras executadas ficaram sob a responsabilidade de dois órgãos baianos: a Companhia de Desenvolvimento Urbano do Estado da Bahia (CONDER) e a Secretaria de Turismo do Estado da Bahia.

De acordo com a CONDER (2012), na llha de Itaparica, particularmente na cidade de Itaparica, foram revitalizados os seguintes elementos: execução de serviços de engenharia para a Urbanização Paisagística e Funcional da Fonte da Bica e do Centro Histórico, além de intervenções para recuperação da estrutura do Solar Tenente das Botas. Além disso, observamos que, mesmo nessa 2a etapa, também não foi contemplada na llha de Itaparica a qualificação (capacitação) profissional, embora essa tenha sido uma proposta dessa etapa.

Considerando, porém, a necessidade de requalificar a região para o turismo, o valor foi irrisório, uma vez que as necessidades são bem superiores. Ao tratar da questão de qualificação e/ou infraestrutura, falamos sobre qualificação e capacitação de mão de obra, melhoria do acesso, estradas, limpeza urbana, recuperação do Patrimônio Histórico, manutenção dos atrativos turísticos, entre outros fatores. Essas características básicas, inclusive, só favorecem o distanciamento de turistas e "novos" turistas para a llha de Itaparica, o que compromete toda a cadeia turística.

Em linhas gerais, o objetivo do PRODETUR/NE I e II foi o fortalecimento dos estados nordestinos em competir na esfera nacional e internacional. Aconteceu de fato um investimento intenso no setor turístico, entretanto, apesar da Costa dos Coqueiros e da Baía de Todos os Santos terem recebido mais investimentos do que as outras zonas, os municípios de Vera Cruz e Itaparica, foram, de certo modo, poucos beneficiados no que tange a tais investimentos.

\section{Procedimentos metodológicos}

Do ponto de vista teórico-metodológico, a elaboração da pesquisa compreendeu um caráter dinâmico à luz das diferentes abordagens teórico-conceituais e do conhecimento empírico. Cumpre salientar que o estudo foi realizado a partir de uma abordagem qualitativa. Conforme Richardson (2007), ao falarmos em abordagem qualitativa, nos referimos ao processo de análise que abrange os 
fenômenos da realidade a partir das movimentações internas e externas, em fluxos convergentes e divergentes, que existem no seio do objeto estudado.

A observação dessas movimentações permite que, de modo mais específico, sejam interpretadas as características, assim como os significados, inerentes tanto ao contexto históricosocial dos fatos estudados, quanto aos fatos propriamente ditos. Nesse sentido, por sua vez, o método de procedimento empregado foi o estudo de caso, o qual foi escolhido porque buscamos analisar o caso da Ilha de Itaparica, considerando-o enquanto um fenômeno particular e, ao mesmo tempo, representativo de outras comunidades, bem como comparável a elas (LAVILLE; DIONNE, 1999).

Além disso, o processo investigativo envolveu também a pesquisa bibliográfica e a cartográfica, bem como a pesquisa em documentação (fontes primárias e secundárias) e arquivos, para além das entrevistas, da observação direta e observação participante. Realizamos, igualmente, a pesquisa de levantamento e, em seguida, a pesquisa de campo, considerada muito importante por englobar a coleta de dados.

A pesquisa de campo foi de cunho explicativo, uma vez que esse instrumento permitiu a utilização de uma variedade de procedimentos de coleta como a aplicação de questionários (cuja finalidade foi o de identificar o perfil dos visitantes) e a entrevista semiestruturada.

As entrevistas foram realizadas com representantes dos órgãos oficiais de Turismo do Estado, municípios e o trade turístico. Para a apreciação das informações coletadas por meio das entrevistas realizadas com os sujeitos escolhidos, utilizamos a técnica de análise denominada de Análise de Conteúdo, uma vez que possibilita que as informações sejam confrontadas com outras já existentes, podendo permitir ampla generalização. Mediante o emprego desta técnica, procuramos analisar, descrever, explicar, por fim, compreender e, ao mesmo tempo, interpretar o que foi possível coletar nas falas dos depoentes (BARDIN, 1977).

\section{Considerações finais}

Em todo o contexto do trabalho, torna-se perceptível a essencialidade de uma inter-relação melhor estruturada entre o planejamento e a dinâmica turística no âmbito do Poder Público. Dessa forma, esclarecemos que ações governamentais são relevantes e que sua aplicação, de maneira coerente, pode proporcionar crescimento e desenvolvimento de forma expressiva e significativa à atividade turística e a toda a sociedade. Acreditamos, dessa forma, que é necessária uma melhor articulação entre o Governo estadual e o terceiro setor no sentido de contribuir efetivamente para melhorias nessas localidades e, desse modo, promover um desenvolvimento planejado e eficiente, colaborando também com a liderança local. Do mesmo modo, vemos como fundamental o 
estabelecimento de parcerias que envolvam o governo estadual, o municipal, o trade turístico e a sociedade como um todo em prol de um desenvolvimento turístico sustentável na llha de Itaparica.

Entendemos, a partir da pesquisa realizada, que o principal problema relacionado à atividade turística na llha se dá pela ausência de planejamento estratégico, o que interfere diretamente na dinâmica de funcionamento dessa atividade. Os dados colhidos e apresentados ao longo desse estudo também sugeriram que essa ausência se deve, em grande parte, à falta de interesse da atuação do poder público, em seus diversos níveis, mas também se refere à falta de articulação das instâncias governamentais com o trade turístico e, consequentemente, com a população como um todo.

Por sua vez, falta, por parte dos empresários, um maior envolvimento na região a fim de dinamizar e aprimorar a atividade turística nessa localidade. Dessa forma, frente ao cenário geral obtido com base na pesquisa empreendida, compreendemos que uma ressignificação da atividade turística na llha de Itaparica só será possível mediante efetivas ações de planejamento para o desenvolvimento sustentável da atividade turística, as quais articulem as instâncias governamentais públicas e a sociedade civil, bem como novas formas de exploração e ampliação dessa atividade na Ilha de Itaparica.

Ao longo dessa pesquisa, procuramos estabelecer inter-relações entre os campos de estudo: Turismo; Planejamento Turístico, Políticas Públicas de Turismo, PRODETUR/NE e Ilha de Itaparica (BA). Estas variáveis foram selecionadas por entendermos que elas compõem a base de sustentação da presente análise, visto que, precisamos do aporte teórico oferecido pelo conjunto desses componentes. Desse modo, após a análise dos dados e das informações provenientes das pesquisas bibliográficas e de campo, foi possível estabelecer algumas relações sobre a dinâmica e a situação da atividade do turismo nesses municípios.

Percebemos, por exemplo, que a ausência de diálogo entre as gestões municipais de Vera Cruz e de Itaparica contribui para a falta de um planejamento conjunto que venha a fortalecer o turismo na região da llha de Itaparica, conforme apontam os dados colhidos nas entrevistas com os representantes das gestões municipais e do trade turístico. Em todo o contexto do trabalho, torna-se perceptível a essencialidade do Poder Público no turismo. Dessa forma, esclarecemos que suas ações são relevantes e que sua aplicação, de maneira coerente, pode proporcionar crescimento e desenvolvimento de forma expressiva e significativa à atividade turística e a toda a sociedade.

Por fim, reiteramos que, enquanto considerações finais, entendemos como fundamental que ocorra, de modo planejado, a formação de parcerias entre as instâncias governamentais estaduais e municipais, o trade turístico e a sociedade civil. Vislumbramos que tais parcerias podem funcionar como uma alavanca para a atividade turística na llha de Itaparica no sentido de que o diálogo 
engendrado entre essas instâncias de atuação e competências diferentes pode levar à configuração de novas rotas turísticas, tendo por base o desenvolvimento sustentável da atividade turística e que se volte às múltiplas potencialidades culturais e paisagísticas que a llha de Itaparica oferece, seja no formato do turismo náutico, do cultural, do ecoturismo ou, mesmo, uma melhor exploração do turismo de sol e praia.

\section{REFERÊNCIAS}

ASSIS, Lenilton Francisco de. A difusão do Turismo de Segunda Residência nas paisagens insulares: um estudo sobre o litoral sul da Ilha de Itamaracá - PE. 2001. 183 f. Dissertação (Mestrado em Geografia) Centro de Filosofia e Ciências Humanas, Universidade Federal de Pernambuco. Recife, 2001a.

BAHIA. Plano de Fortalecimento Municipal da Gestão do Turismo e do Patrimônio Natural e Cultural. Itaparica (Bahia). Secretaria do Turismo da Bahia, Brasil, 2012.

BARDIN, Laurence. Análise do Conteúdo. Lisboa, Edições 70, 1977.

BRASIL. Ministério do Turismo. Secretaria de Políticas de Turismo. Programa de Qualificação a Distância para o Desenvolvimento do Turismo: formação de gestores das políticas públicas do turismo. NETTO, Alexandre Panosso; SILVA, Francisco José Pereira; TRIGO, Luiz Gonzaga Godoi (ORG). Florianópolis: SEAD/FAPEU/UFSC, 2009. 312 p.

GAUDENZI, Paulo Renato Dantas. Planejamento \& Experiências: turismo na Bahia. Salvador: Omar Editora, 2008. 200 p.

Bahiatursa. 30 anos 1968-1998. Empresa de Turismo da Bahia. Salvador, 1998. 96

p.

INSTITUTO BRASILEIRO DE GEOGRAFIA E ESTATíSTICA. 2010. Disponível em:<www.biblioteca.ibge.gov.br>. Acesso em 20 de Maio de 2015.

ITAPARICA (BA). Prefeitura Municipal. Plano Diretor de Desenvolvimento Urbano de Itaparica. Salvador: Companhia de Desenvolvimento e Ação Regional- CAR (BA), 2003 - 2005. 6v.

LAVILLE, Christian; DIONNE, Jean. A construção do saber: manual de metodologia da pesquisa em ciências humanas. Porto Alegre: Editora UFMG, 1999.

MATTEDI, Maria Raquel Mattoso. Planejamento e Gestão do Turismo e do Meio Ambiente na Bahia. In: Gestão \& Planejamento, v.1, № 1. UNIFACS,1999. p. 01-21.

MOLINA, Sergio. RODRÍGUEZ, Sergio. Turismo: Planejamento Integral: um enfoque para a América Latina. Bauru, SP: EDUCS, 2001.

OSÓRIO, Ubaldo. A Ilha de Itaparica: história e tradição. Salvador: Fundação Cultural do Estado da Bahia, 1979. 564 p.

RICHARDSON, R. Pesquisa social: métodos e técnicas. 3. Ed., São Paulo: Atlas, 2007. 
SANTOS, Dário Tavares. Heranças e lembranças: educação, patrimônio cultural e desenvolvimento em Itaparica. 2011. 210 f. Dissertação (Mestrado) - Universidade do Estado da Bahia, Programa de Pós-Graduação em Educação e Contemporaneidade. Departamento de Educação, 2011.

SOARES, Cláudia Mesquita Pinto. Dinâmica do Turismo na Baía de Todos os Santos: O caso da llha de Itaparica. 2003. 194 f. Dissertação (Mestrado em Análise Regional). Departamento de Ciências Sociais Aplicadas. Universidade Salvador (UNIFACS). Salvador, 2003. 
